\title{
ANALYSIS OF ERP IMPLEMENTATION EFFECTIVENESS OF A PLANTATION COMPANY IN INDONESIA
}

\begin{abstract}
The evaluation of Enterprise Resource Planning (ERP) implementation effectiveness in a company is very important as it helps in analyzing the benefit that the company receives from the system. One of the methods that can be used to measure the effectiveness of ERP implementation is Analytical Hierarchy Process (AHP). This study aims at analyzing the effectiveness of ERP implementation at a plantation company in Indonesia by using AHP. We identify criteria that affect the implementation of ERP based on the literature and interviews with experts from the company, who also score all the criteria. The results show that the identified criteria are strategy-fit, change management, business functionality, flexibility, and benefit. The results also show that ERP has a positive impact to the company. However, it still needs some improvement to maximize its effectiveness.
\end{abstract}

Keywords: ERP implementation, AHP.

\section{Introduction}

Information technology (IT) can be used as strategic decision support system, especially in determining the company's direction and supporting its strategy. An example of IT application that supports the company's operations and managerial decision making is Enterprise Resource Planning (ERP). Motiwala and Thompson (2009) defines ERP as a system that aims to integrate the company's data comprehensively to support all organization functions. ERP can accelerate information flows and increase the usefulness and value of data, and reduce its input redundancy. However, ERP is a huge investment due to its expensive price/cost, and some companies fail in the implementation stage, and therefore fail to experience its benefit. This research aims at analyzing ERP implementation effectiveness at an Indonesian oil palm plantation company (PT. XYZ) using AHP as currently some users of the system fail to experience its benefit.

\section{Literature Review}

According Word and Magal (2012), ERP is a system that is huge and more complex than enterprise system. Companies choose to employ ERP system to improve the supply chain efficiency, increase customer access to their products and services, reduce operations costs, quickly respond to market changes, and deliver business intelligence from the available data (Motiwala dan Thompson, 2009). Xu (2012) identifies four criteria that affect the success of ERP implementation, namely organizational strategic, organizational tactical, technological strategic, and technological tactical. Teltumbde (2000), however, identifies ten criteria that can be used to evaluate ERP implementation effectiveness, namely strategy fit, technology, change management, risk, implementability, business functionality, vendor credentials, flexibility, cost, and benefit.

\section{Hypotheses/Objectives}


ISAHP Article: Paper Proposals To Be Submitted to the International Symposium on the Analytic Hierarchy Process 2016, London, U.K.

This research aims at identifying key success factors of ERP implementation at PT.XYZ, and develop a model to analyze its current effectiveness to provide input for improvement to the management.

\section{Research Design/Methodology}

The model to determine ERP implementation effectiveness is developed based on criteria found in Teltumbde (2000) and results of in-depth interviews (IDIs) with experts from the company. In total, six experts are involved in the process of determining criteria, criteria weights and scores. Weights of criteria are determined by using pairwise comparisons, we make sure that the inconsistency level is not higher than 0.1. Aggregated weight for each criterion is then calculated by averaging the weights form all experts. Criterion score is assigned in the range of 1 to 10 .

\section{Data/Model Analysis}

The criteria used in the model are strategy fit, change management, business functionality, flexibility, and benefits. The decision making model to determine ERP implementation effectiveness is depicted in the following figure.

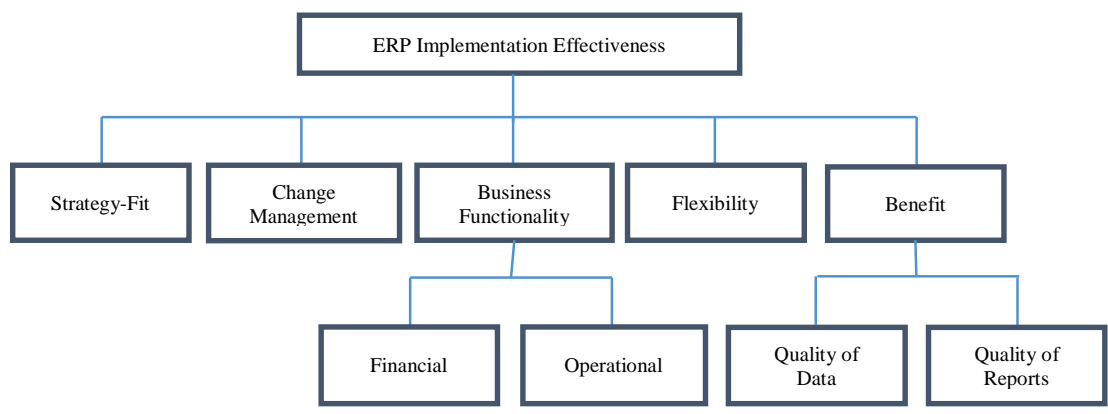

Analysis of the weights and scores results in the total score is 7.589 , indicating that the ERP implementation still need to be improved to maximize the benefit for the company.

\section{Limitations}

Financial benefit of ERP implementation has not yet been considered in the model.

\section{Conclusions}

We develop the model to analyze the ERP implementation effectiveness for a plantation company in Indonesia. The model uses criteria that are based on literature and has taken into accounts company's representatives opinion. The results indicate that the ERP implementation at PT. XYZ still need to be improved, especially in supporting operations and improving the quality of data and reports.

\section{Key References}

Motiwala, L.F., Thompson, J. (2009). Enterprise Systems for Management. New Jersey: Pearson Prentice Hall.

Teltumbde, A. (2000). A Framework for Evaluating ERP Projects. International Journal of Production Research, 17, 4507-4520.

Word, J., Magal, S.M. (2012). Integrated Business Process with ERP Systems, United States: John Wiley \& Sons, Inc.

Xu, L. (2012). The Evaluation of ERP Sandtable Simulation Based on AHP. Journal of School of Management, Tianjin University of Technology, 1924-1931. 